\title{
Interpretación estratigráfica de Numancia y ordenación cronológica de sus cerámicas
}

\author{
Stratigraphic Interpretation of Numantia and \\ Chronological Ordering of its Pottery
}

Recibido: 12-03-2012

Aceptado: 13-06-2012

\author{
Alfredo Jimeno, Antonio Chaín, Sergio Quintero, Raquel Liceras, Ángel Santos \\ Equipo Arqueológico de Numancia, Departamento de Prehistoria, Universidad Complutense. \\ aljimen@ghis.ucm.es
}

\begin{abstract}
RESUMEN
Este artículo aborda la cuestión estratigráfica de Numancia, tratando de resolver el número de ciudades superpuestas $y$, en relación con este tema, el de la ordenación de sus cerámicas, que están sin solucionar desde los inicios de su investigación hace más de doscientos años, y que han condicionado en gran medida la cronología y ordenación de los yacimientos celtibéricos. Se analizan las aportaciones de los investigadores anteriores, teniendo en cuenta las nuevas claves propiciadas por las excavaciones recientes, que permiten abrir nuevas perspectivas interpretativas.
\end{abstract}

Palabras clave: Estratigrafía. Cronología cerámica. Celtibérico. Romano. Numancia.

\begin{abstract}
This article deals with the main stratigraphic problem of the Celtiberian town of Numantia, trying to settle the question of the number of superimposed cities and, related to that problem, the chronological seriation of its ceramics, which remains unsolved since the beginning of research more than two hundred years ago, and have seriously conditioned the chronological interpretation of the rest of Celtiberian sites. Contributions of previous researchers are analyzed, taking into account the new evidence brought about by recent excavations, which allows opening new interpretative perspectives.
\end{abstract}

KEY wORDS: Stratigraphy. Ceramic chronology. Celtiberian. Roman. Numantia.

Sumario 1. Introducción. 2. El problema estratigráfico. 3. La cronología de las cerámicas. 4. La excavación de la Manzana-XXIII. 5. Yacimientos con cerámica de tipo numantino. 6. Discusión. 7. Conclusiones. 


\section{Introducción ${ }^{1}$}

Uno de los problemas, no resuelto todavía en $\mathrm{Nu}-$ mancia desde los inicios de su investigación hace más de doscientos años, es la cuestión estratigráfica, ya que no se ha podido identificar con concreción el número de ciudades superpuestas y su contexto cronológico y cultural. Las propuestas realizadas por diferentes investigadores contemplan la posibilidad de existencia de entre dos y cuatro ciudades, no habiendo tampoco coincidencia en si las identificadas corresponden a época celtibérica o romana.

Las dificultades para solucionar de una manera nítida este problema las hemos ido viendo a lo largo de estos años de trabajo en Numancia, pero se han hecho más evidentes en los últimos años, ya que la amplitud de la excavación de la Manzana XXIII nos ha permitido tener una mayor información que la que se puede obtener a través de pequeñas catas. No obstante, teniendo como referencia la documentación que nos han transmitido los arqueólogos que nos precedieron, podemos entender todavía mejor su trabajo y las dificultades que encontraron para diferenciar los distintos horizontes estratigráficos, lo que permite entender que "nunca se precisara ni se llegase a establecer su diferenciación más que como un conjunto de estratos incendiados revueltos y calificables, de modo acorde con la Numancia destruida" por Escipión (Wattenberg1972: 66). Este artículo pretende ser un homenaje a los que nos precedieron, ya que todo él no sería posible sin la valiosa información que ellos nos han legado.

\section{EI problema estratigráfico}

No entraremos en este artículo a considerar las ocupaciones conocidas en el cerro de La Muela de época calcolítica y del final de la Edad del Bronce-inicios de la Edad del Hierro, de las que se registraron una serie de restos hallados en diferentes zonas del yacimiento, que han sido ya estudiados (Fernández 1997; Jimeno y Chaín 2005-2006: 254), sino que nos centraremos exclusivamente en la problemática que plantea la superposición de ciudades celtibéricas y romanas (Jimeno y Tabernero 1996: 415; Jimeno et al. 2002)

2.1 A. Schulten, en los trabajos que realizó en 1905, con la competencia de Koenen, en la Manzana IV diferenció tres trazados urbanísticos: uno inferior, que denominó ibérico, de casas rectangulares en dirección este-oeste, con la puerta situada hacia el último punto y con sendas estancias subterráneas o cuevas, dejando una calle de ronda entre su parte trasera y la muralla, con capa de incendio y cerámicas "ibéricas"; otro intermedio de tierras amarillentas y muros caídos de tapial, bien diferenciado, al que denominó ibero-romano, también de casas rectangulares pero de mayor tamaño, que cruzan sobre las anteriores con una orientación noroeste-sureste adosándose a la muralla por uno de sus lados estrechos; finalmente registró la urbanística más moderna, de época imperial romana con casas de estructura y compartimentación más amplia y compleja.

Esta estratigrafía es la más completa de las conocidas en Numancia. La continuidad de la urbanística intermedia, denominada ibero-romana, de casas rectangulares con mayor dimensión $(12 \mathrm{~m} \times 6 \mathrm{~m})$ y adosadas a la muralla se ha localizado también en el Barrio Sur (Manzana-I), amortizada por la ciudad romana posterior: de hecho uno de los aljibes cuadrados de esta última rompe claramente un muro de una de estas casas (Schulten 1945: 170) (Figs. 1 y 2 ).

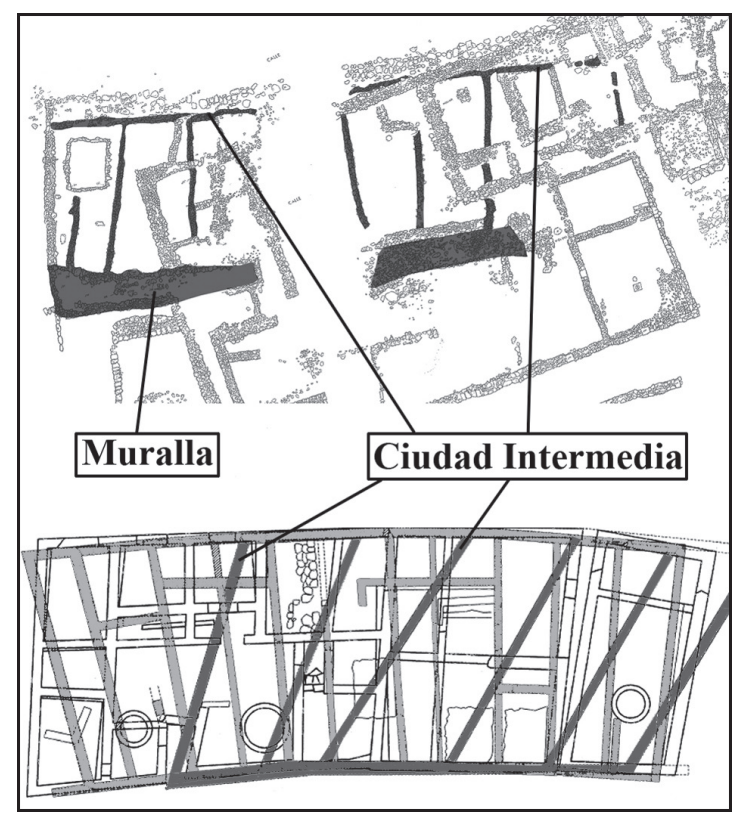

Figura 1.- Casas rectangulares de la urbanística intermedia (entre 133 y 75 a.C.), adosadas a la muralla, amortizada.

2.2 La Comisión de Excavaciones, que realizó sus trabajos entre 1906 y 1923, diferenció dos ciudades, una de ellas más antigua y que denominó ibérica, relacionándola con la urbanística visible de calles con piedras pasaderas, algo refrendado por Taracena (1924: 77): "sólo las (cerámicas) del final de esta técnica bicromada, las de simples ornatos geométricos, se hallaron con sencillos vasos de pinturas 


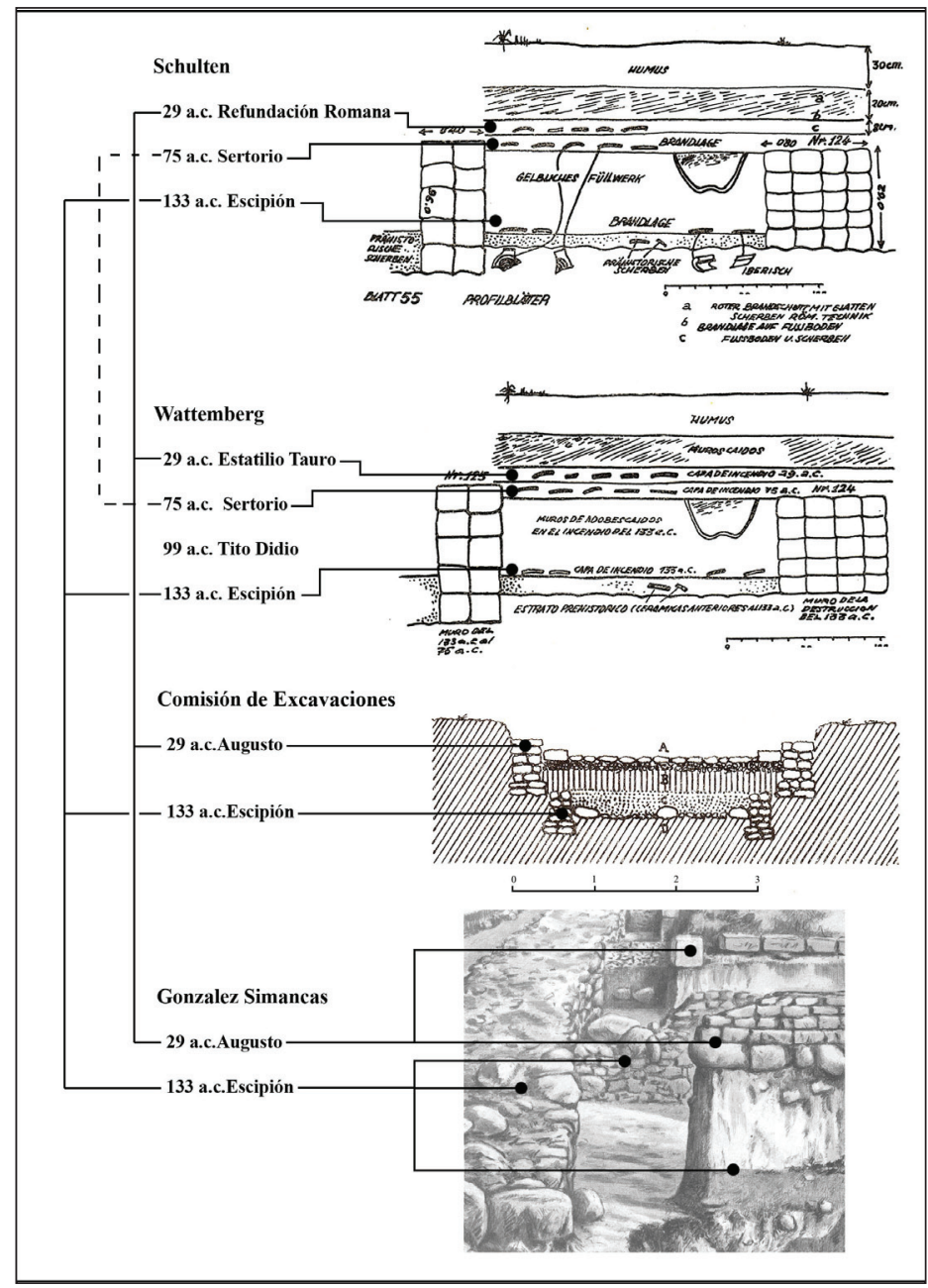

Figura 2.- Interpretaciones estratigráficas de los diferentes investigadores.

negras, también geométricas, sobre el pavimento de las calles ibéricas...o aplastadas y machacadas inmediatamente debajo de la pavimentación de algunas habitaciones romanas"; relacionaba con esta ciudad también las estancias subterráneas "en las cuevas que los romanos no revolvieron...se encuentran aplastadas las tinajas rojas de círculos concéntricos o algunos de los mayores vasos negros".

Estas observaciones llevaron a la Comisión de Excavaciones a hablar únicamente de dos ciudades, una la destruida por Escipión en el 133 a.C., de calles con piedras pasaderas, que quedaría abandonada y no se volvería a ocupar hasta época de Augusto, ajustándose esta última, en gran medida, al trazado urbanístico de la anterior y quedando reflejadas las dos ciudades superpuestas sobre el plano realizado de la ciudad (Fig. 2). No obstante, resulta difícil de entender que dos ciudades alejadas en el tiempo, al menos un siglo, pudieran ajustarse tan estrechamente en su trazado; además, a lo largo de ese tiempo de abandono, se deberían de haber acumulado sobre los restos de la ciudad más antigua los materiales de su destrucción, así como cierta capa sedimentaria que se habría reflejado en el proceso de excavación, impidiendo que fuera tan visible la ciudad inferior como para acomodar la otra encima. Es entendible la relación que se establece entre las cerámicas celtibéricas, junto a restos de incendio y destrucción, halladas tanto en la base de las calles de la ciudad inferior como en las "cuevas" o estancias subterráneas, pero ninguno de los dos casos guarda relación con esta ciudad, como explicaremos posteriormente.

La excavación de las defensas de Numancia fue encomendada por la Comisión de Excavaciones al investigador castrense González Simancas (1926), que excavó un tramo de muralla de la zona este y sus construcciones adosadas, señalando bastante confusamente la existencia de diferentes niveles de los que dos correspondían con los de la Comisión: 
a una ciudad incendiada celtibérica (la supuesta del 133 a.C.), que relacionó con las cerámicas pintadas que aparecían inmediatamente debajo de la romana, se le superponían destrucciones y rellenos, el último fechado por la aparición de una moneda de Claudio el Gótico (268-270 d.C.) (Fig. 2).

2.3 F. Wattenberg será quien, cuarenta años después de los trabajos de la Comisión, vuelva a abordar, en su trabajo Las cerámicas indigenas de $\mathrm{Nu}$ mancia (1963), el tema estratigráfico recogiendo la aportación de los autores que se habían ocupado anteriormente de Numancia y teniendo en cuenta sobre todo las de Schulten. En la interpretación que realiza de la estratigrafía del investigador alemán deduce tres niveles de destrucción e incendio, que corresponderían a tres ciudades indígenas con anterioridad a la ciudad romana imperial, aunque Schulten, como hemos visto anteriormente, se refiere sólo a dos niveles indígenas (Fig. 2).

Para dar una cronológica a los diferentes niveles de incendio plantea relacionarlos con acciones bélicas constatadas en los textos romanos, atribuyendo los tres niveles al 133, 75 y 29 a.C. Para Wattenberg, las dos plantas de ciudades -consideradas celtibérica y romana-, recogidas en el plano clásico elaborado por la Comisión de Excavaciones serían posteriores al 133 a.C.: la inferior, de calles con piedras pasaderas, sería destruida en el 29 a.C. por Statilo Tauro, que realizó campañas contra vacceos, cántabros y astures, para ser reconstruida casi inmediatamente en época de Augusto, lo que explicaría según Wattenberg la gran concomitancia existente entre el urbanismo de ambas. Es asumible la propuesta que hace Wattenberg al considerar estas dos ciudades posteriores al 133 a.C., pero resulta difícil aceptar que la más antigua fuera destruida en el 29 a.C. por Statilo Tauro, ya que no está constatado ataque alguno de éste contra Numancia, ni hay constancia de que en ese momento existiera la ciudad.

Posteriormente, pero el mismo año de la publicación de su trabajo sobre las cerámicas, Wattenberg (1972: 66-71) llevó a cabo cortes estratigráficos en Numancia, realizando dos trincheras paralelas de $30 \mathrm{~m}$ de largo y uno de ancho. No tuvo dificultad para identificar un primer nivel romano a escasa profundidad (de 20 a $30 \mathrm{~cm}$ ), con construcciones de muros de piedra y restos de estuco, pero manifiesta, no obstante, los problemas que encuentra para diferenciar los estratos indígenas de la estratigrafía de Schulten, al detectar debajo solamente un nivel de características muy diferentes a las romanas, con cerámicas monócromas y polícromas, "ya que las habitaciones... se excavan sobre un lecho natural de greda rojiza, utilizando como complemento adobe". Es decir, encuentra la misma información y composición que la Comisión de Excavaciones, así como la observada por nosotros al excavar la Manzana XXIII.

Wattenberg imagina una ciudad celtibérica antigua con casas excavadas en el manto natural, por lo que los muros no estarían realmente construidos, sino que serían las paredes mismas del manto natural, y plantea que muchas de estas casas y por tanto el nivel antiguo hayan podido desaparecer al ahondar en el suelo para asentar las ciudades posteriores. No obstante, resulta un tanto sorprendente que interprete una ciudad con casas excavadas en la greda cuando ya los trabajos de Schulten habían reconocido la existencia de una ciudad inferior de casas rectangulares con sus muros y con estancias subterráneas o "cuevas" con cerámicas de distintos tipos, a las que se accedía por una trampilla de madera (Fig. 3).

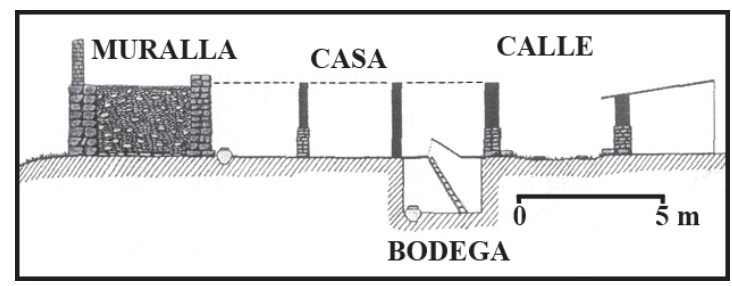

Figura 3.- Reconstrucción de una de las casas rectangulares del nivel inferior (133 a.C.), con una estancia subterránea (según Schulten 1945).

\section{La cronología de las cerámicas}

En la propuesta de B. Taracena (1924), en su Tesis Doctoral sobre las Cerámicas Ibéricas de Numancia, plantea una evolución en tres estilos, desde el naturalismo (vasos blancos o blanco-amarillentos y pinturas polícromas naturalistas, s. IV-III a.C.), pasando por el geometrismo (vasos rojos y pinturas bícromas tendentes a lo fantástico con carácter barroquizante, mediados del s. III a.C.), para llegar al esquematismo (figuras geométricas en negro sobre vasos rojos, desde fines del s. III hasta el 133 a.C.). El inicio de las cerámicas bícromas lo vincula con un origen celta, pero asumiendo que progresivamente se acusará más la influencia mediterránea, concretamente griega, que dejará su poso en las cerámicas monócromas. Este planteamiento con referencias al origen celta se verá desplazado por la influencia de las cerámicas ibéricas (Romero 1976: 182).

Las cerámicas se habían ordenado estilísticamente, estableciendo grupos y cronologías e incluso asignando distinta filiación étnica para diferentes fases (Romero 1976: 183), pero lo que no cambiaba 
era su momento final, en el 133 a.C. Será Wattenberg 1959: 151ss) quien plantee que ha de rebajarse la cronología de las cerámicas numantinas y vincular su origen al contexto celtibérico, planteando un esquema de ordenación distinto al de Taracena (1924), ya que la pintura surgiría a partir de la llegada de los segedenses a Numancia (154 a.C.) y la evolución de las formas y técnica de fabricación de los vasos polícromos, más avanzados, sería un fenómeno que aparecería en un momento tardío de la producción, planteando una cronología más allá del 133 a.C.

Para apoyar estos planteamientos era necesario acometer una revisión de la estratigrafía como base imprescindible para la ordenación y cronología de la cerámica, que desarrolló en un trabajo de referencia, ya comentado (Wattenberg 1963). La utilización industrializada del torno mantendría las formas tradicionales, apareciendo las típicas cerámicas celtibéricas pintadas (179 y 133 a. C); a continuación se desarrollarían los temas con motivos simples (133 y 75 a.C.); en una tercera fase se produciría una exaltación de la temática indígena, apareciendo formas de tipología mixta indígenas y romanas, con decoración monocroma y al final de la evolución de este proceso, la policromía en los vasos, como influencia ya romana y preludio de la cerámica tipo Clunia (75 y 29 a.C.). De esta manera las cerámicas numantinas tenidas como más genuinamente celtibéricas por Taracena y relacionadas con la ciudad destruida en el 133 a.C. se situaban en el siglo I a.C., bajo influencia romana (fig. 4).

No faltaron críticas a Wattenberg sobre la solidez de su propuesta, ya que conllevaba que las cerámicas posthallstátticas o del inicio de Cogotas II llegaran hasta una fecha muy tardía, como el 133 a.C., cuando ya en esta fecha se asumía el desarrollo de las cerámicas finas a torno (Palol 1972: 102). No obstante, el trabajo de F. Romero (1976: 185-187) Las Cerámicas Polícromas de Numancia reforzaba la propuesta del autor alemán, al plantear la influencia de los anversos de la monedas de cecas, como Secaisa, Arsaos y Bascunes, en la configuración de los rostros de algunas representaciones humanas numantinas; así como las figuras zoomorfas en perspectiva cenital de las cerámicas, con referencias a este tipo de representaciones a una tessera y cerámicas que se fechaban a mediados del s. I a.C.

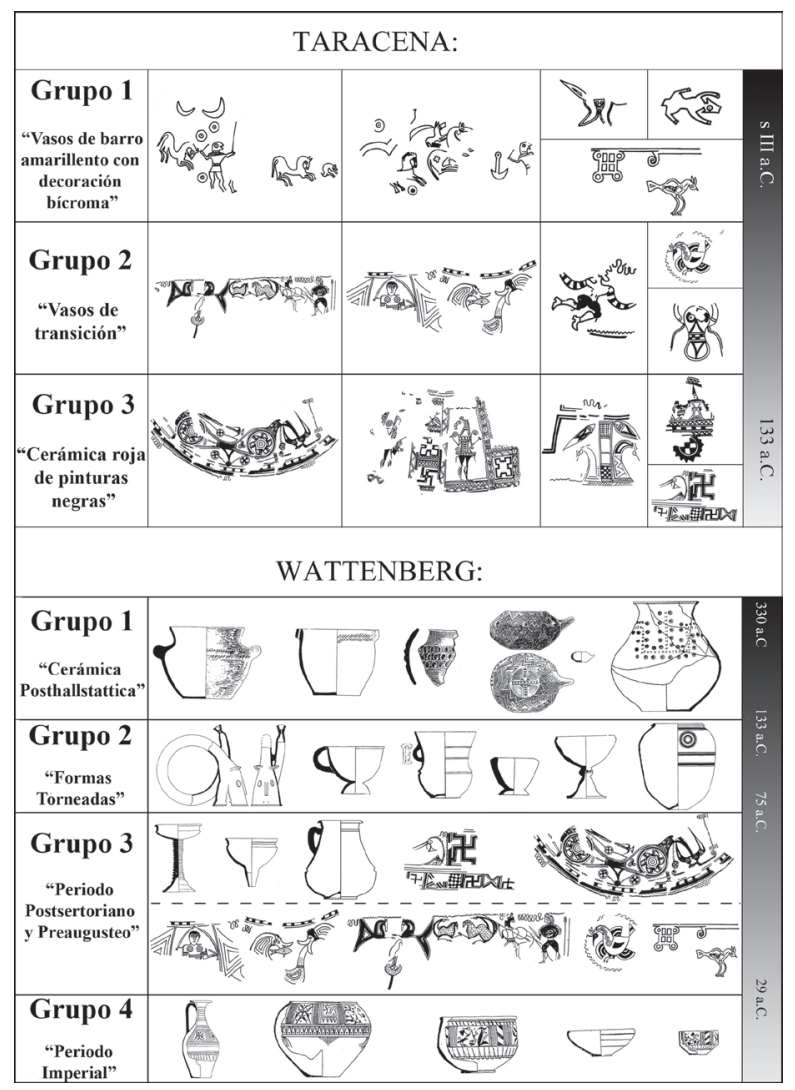

Figura 4.- Ordenación cronológica de los diferentes grupos de la cerámica numantina, según Taracena (1924) y Wattenberg (1963). 
Será Sacristán (1986: 121), en su trabajo sobre la Edad del Hierro en el Valle Medio del Duero, quien denuncie el encorsetamiento propuesto por Wattenberg, atando los cambios estratigráficos a acontecimientos bélicos -salvo el referido a las Guerras Sertorianas, constatado y coincidente en numerosos yacimientos- y llamando la atención sobre la posibilidad de que el registro arqueológico pueda mostrar la conflictividad entre los pueblos indígenas, así como sucesos naturales de destrucción e incendio.

Por otro lado, nuevos datos apoyaban la presencia del torno a partir del s. IV a.C., demostrando Sacristán (1986: 132) cómo la plena etapa celtibérica abarcaría de lleno el s. II a.C., prolongándose hasta la mitad del s. I a.C., situando dentro de esta etapa clásica la mayor parte de los elementos materiales que Wattenberg incluía en sus etapas "postsertorianas" o "preaugústeas", que llevaba desde el 75 hasta el 29 a.C. No obstante, asume que la cerámica del Valle del Duero, siendo deudora de la ibérica, presenta una estética diferente, más sobria y austera, destacando no obstante la excepcionalidad del barroquismo de las producciones numantinas y su policromía (en las cerámicas vacceas, solamente se conocen una línea roja más intensa que el fondo del vaso entre dos líneas negras más estrechas); asimismo, los motivos figurados, a diferencia de Numancia, no llegaron a calar en la zona del Duero Medio. Ante este panorama, Sacristán (1986: 192) se preguntaba: ¿pero es que se puede remontar el figurativismo numantino hasta esta época?, contestándose que las sistematizaciones evolutivas realizadas hasta entonces no ofrecían suficientes garantías para su aceptación.

\section{La excavación de la Manzana XXIII}

Esta manzana, de época romana y anterior, es de forma rectangular $\left(60 \mathrm{~m} \times 24 \mathrm{~m}=1450 \mathrm{~m}^{2}\right)$ y tiene uno de sus lados estrechos abierto a la calle B, una de las principales de Numancia, que junto con la $\mathrm{D}$, son las más largas y únicas que recorren la ciudad de norte a sur, articulando el resto de la ordenación urbana de calles transversales, orientadas en dirección este-oeste. Se trata de una planificación general para toda la ciudad, mostrando una actuación edilicia que impone el trazado de las calles con aceras y la delimitación de las manzanas por medio de un muro de mayor grosor.

El interior de la manzana se estructura diferenciando, en su zona central, un conjunto de casas, separadas en su parte posterior por un muro medianero longitudinal, algo más grueso, que condiciona su acceso por calles paralelas opuestas, y otro transversal de similares dimensiones. A uno y otro lado del grupo de casas se aprecian sendos espacios que parecen abiertos, con acceso desde la calle a modo de patios y en los lados estrechos diferentes recintos independientes que muestran vocación hacia la calle, a modo de tiendas talleres y almacenes, diferenciándose en la esquina noreste un gran aljibe cuadrangular para el abastecimiento de agua (fig. 5).

\subsection{Referencia cronológica para la urbanística romana}

Ha sido posible relacionar claramente la base de la urbanística visible de la ciudad de piedras pasaderas con sigillatas itálicas, que permiten fechar esta urbanística en las primeras décadas del reinado de Augusto, lo que será objeto de un próximo trabajo. Según parece deducirse de la excavación de la Manzana XXIII, es posible que las dos ciudades en las que se basó la Comisión de Excavaciones (1906-1923) para hablar de una ciudad celtibérica antigua, destruida por Escipión en el 133 a.C. y que quedaría abandonada y no se volvería a ocupar hasta época de Augusto, sean ambas de época imperial romana y no se trate tanto de una superposición como del acondicionamiento y el reajuste urbanístico de la ciudad romana inicial, como indican los restos arqueológicos, hacia un trazado más rectilíneo y ortogonal. Este reajuste va asociado a materiales del final de época flavia, cuando Numancia recibe el ius Latium (Espinosa 1984: 317), registrándose otro momento de abundancia de materiales a partir de Domiciano y los primeros Antoninos (sigillatas con sellos de Senilis y Aemilivs y otras cerámicas), ya que hay que anotar que los materiales más modernos de esta manzana no pasan de la época de Adriano, del que se han encontrado varios ases.

La planificación de esta manzana no muestra rectificaciones significativas, indicando que su trazado se mantuvo a lo largo del tiempo. Es en el interior de la manzana, es decir en los ámbitos privados, donde observamos rectificaciones o superposiciones de muros que modifican los espacios, lógica consecuencia de tener que atender a las necesidades familiares o cambios de usos que surgieron a lo largo del tiempo.

\subsection{La urbanística celtibérica oculta por la manzana romana}

El muro perimetral de la manzana romana corta los restos de una urbanística celtibérica inferior, 


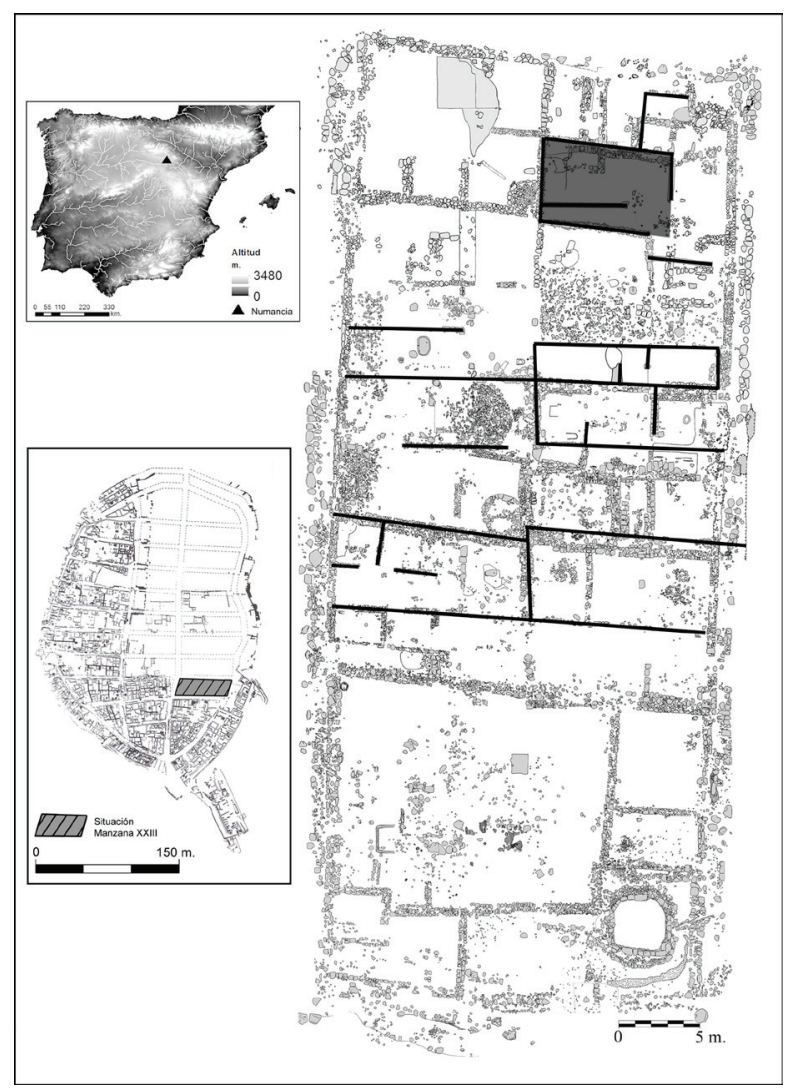

Figura 5.- La Manzana XXIII con su ubicación en el plano de la ciudad, con el nivel romano y celtibérico (línea negra).

de casas rectangulares y esquema urbanístico totalmente diferente. Se ha podido documentar un conjunto de casas completamente quemadas, de las que se ha conservado sólo la parte inferior de algunas al estar embutidas en el manto natural, y al haber sido éste enrasado "intencionadamente", mediante la colmatación de las zonas rebajadas con los restos de paredes y techumbres caídas, antes de llevar a cabo la construcción de esta manzana en el marco de la planificación urbanística de la ciudad de época romana. La excavación ha permitido asociar con claridad los materiales celtibéricos con los resquicios de los fondos de las casas pero, cuando estos no existen, aparecen dispersos y mezclados con los romanos, incorporados a la base de las calles y de los suelos de tierra apisonada de las casas romanas. Entendemos que este hecho es lo que llevó a pensar a los arqueólogos de la Comisión de Excavaciones que había una ciudad inferior celtibérica y otra superior romana, con escasas diferencias urbanísticas entre ellas (Fig. 5).

Las casas celtibéricas son las típicas de planta rectangular y tripartita, con cierta diferencia de anchura entre ellas e incluso algunas con dependencias añadidas a modo de almacén. Al parecer, estaba organizada la ciudad en grupos de casas de unos $30 \mathrm{~m}$ de ancho, ordenadas en dos hileras de casas abiertas por uno de sus lados estrechos, cada una a una calle, y estableciendo medianería por el lado estrecho posterior y uno de sus lados largos. Sin duda alguna, estas casas, por sus características, guardan relación con la urbanística celtibérica más antigua que Schulten documentó en la Manzana IV.

\subsection{La casa celtibérica del almacén y su conte- nido}

Entre las casas celtibéricas documentadas, la que más información ha proporcionado es la que hemos denominado Casa 2, de la que solamente se han podido excavar parcialmente dos de sus habitaciones, por haber sido cortadas por la urbanística romana posterior y una tercera completa que estaba bastante bien conservada y con numerosos materiales almacenados en ella. Esta casa, como el resto de las documentadas, había sufrido un fuerte incendio, por lo que los restos de las paredes y techumbres colmataban y rellenaban el rehundido 
de base de la estancia, que tiene forma rectangular $\left(7,66 \mathrm{~m} \mathrm{x} 4 \mathrm{~m}=30,64 \mathrm{~m}^{2}\right)$, estando dividida, aunque no en toda su longitud, por un pequeño murete de adobe que separa dos superficies trapezoidales, de 8,60 y $22 \mathrm{~m}^{2}$ respectivamente (Figs. 5 y 6 ).

La compartimentación pequeña estaba vacía; por el contrario, la grande estaba repleta de materiales que, a pesar de su deterioro, conservaban una distribución ordenada. Se aprecian tres zonas perfectamente diferenciadas: los dos extremos destacan por la presencia de grandes vasijas de contención de alimentos (dos en el lado norte y tres en el sur) que se hallaron in situ, ligeramente encajadas sus bases en el suelo natural apisonado y, en torno a ellas, abundantes elementos de vajilla. Por el contrario, el espacio central debía estar despejado ya que los materiales fragmentados, que se han encontrado sobre el suelo, proceden, por las características de su dispersión, de una alacena que estaría situada sobre un banco corrido de la pared oeste. Se han hallado un total de 95 objetos, correspondiendo una mayoría a cerámica (copas, cuencos, ollas, vasos, jarros o bock, jarras, pucheros, tapaderas, morteros, grandes vasijas, fichas y canicas) y, en menor medida, útiles de metal y hueso (agujas de coser, chapas, punzones de hierro enastados en sus mangos de hueso, cuchillas, pesa de piedra, un anillo de bronce y un magnífico molde de fíbula anular) (Santos et al. 2012).

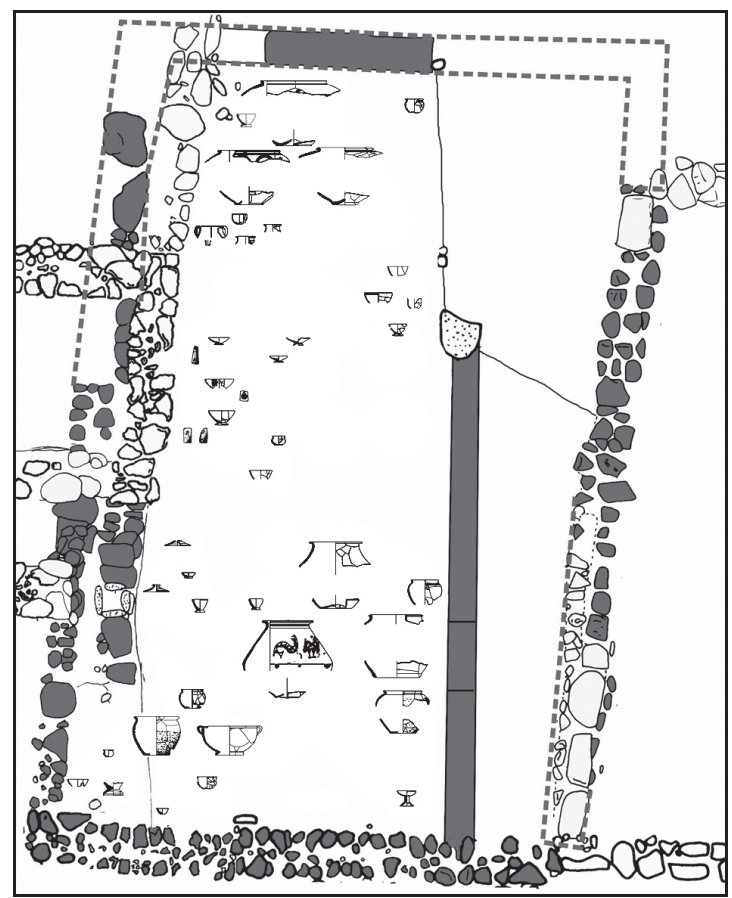

Figura 6.- El almacén de la casa celtibérica de la Manzana-XXIII.
De estos objetos destaca por su peculiaridad decorativa e iconográfica una de las grandes vasijas, que forma parte de una serie de contenedores caracterizados por tener su cuerpo de forma bitroncocónica, pequeño cuello y borde exvasado: anchura de boca $26,4 \mathrm{~cm}$; diámetro máximo $54 \mathrm{~cm}$; fondo 12 $\mathrm{cm}$ y una altura aproximada de $54 \mathrm{~cm}$. La decoración, como es usual en este tipo de grandes vasos, se desarrolla en la zona superior entre el borde y la carena central, por ser la más visible, al estar depositados en el suelo. Previamente a la realización pictórica con línea negra, se le aplicó una capa de engobe blanco, que está bastante perdido (Fig. 7).

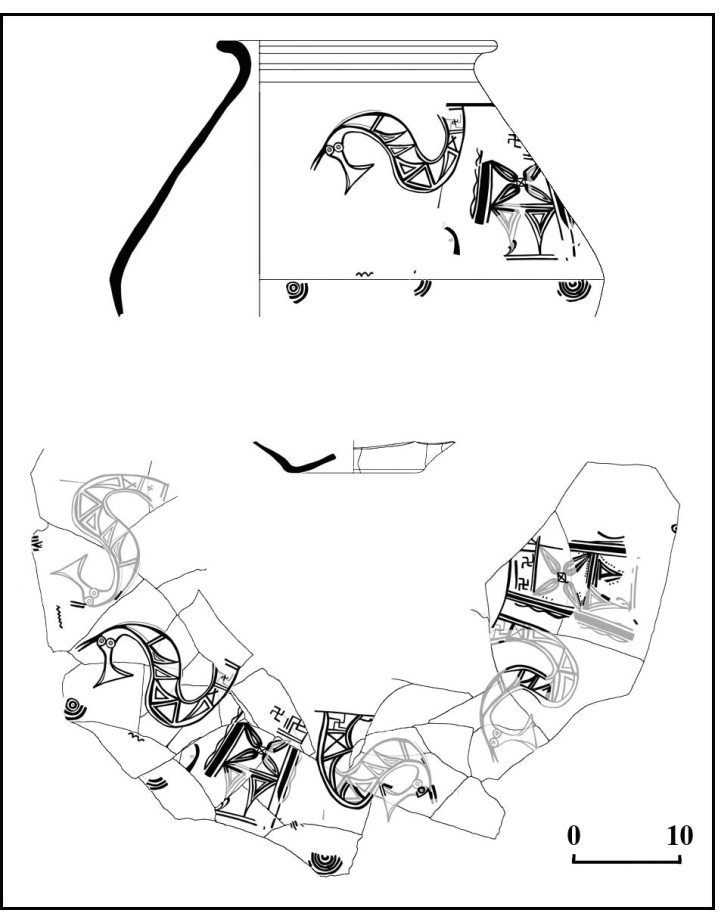

Figura 7.- Vasija hallada en el suelo del almacén de una casa celtibérica.

El esquema decorativo se desarrolla en horizontal, de forma continua, interrumpido por dos anchas franjas verticales, a modo de metopa, que enmarcan de forma repetida la representación de dos figuras híbridas contrapuestas con cabeza de caballo y cuerpo serpentiforme. Los elementos verticales de la decoración están compartimentados en tres ámbitos: uno superior con dos tetrasqueles, en dirección levógira; otro central con cuatro esquematizaciones de peces, que confluyen en el centro, tocando cada uno con su "boca" los vértices de un pequeño cuadrado y el inferior con dos esquemas triangulares, a modo de soportes de los campos situados encima. Los cuatro caballos serpentiformes presentan un es- 
quema decorativo similar: cabeza con el típico hocico aflautado, finas orejas puntiagudas y grandes ojos, que miran fijos y frontalmente, algo muy característico de los artistas numantinos, (Wattenberg 1963: láms. II-VII). El cuerpo serpentiforme está decorado con elementos triangulares, presentando dos espacios trapezoidales al final, decorado el más interior con un aspa y el exterior o extremo con un tetrasquel en dirección levógira, que coinciden con los representados en las franjas verticales; trazos de líneas vermiformes se disponen por debajo de estos híbridos, rematando la franja decorativa, a la altura de la carena, con una serie de semicírculos concéntricos, dispuestos hacia abajo (Liceras et al. 2012).

Esta vasija está asociada entre otras cerámicas a copas, cuencos y vasos pintados con línea negra: círculos y semicírculos concéntricos, franjas horizontales metopadas y ollas grises con decoración estampillada de círculos concéntricos. Según Taracena estas cerámicas estarían relacionadas con la ciudad celtibérica, destruida por Escipión en el 133 a.C., mientras que Wattenberg las pondría en relación con la ciudad que se desarrollaría entre el 75 y el 29 a.C. Estaban cubiertas todas ellas por vigas y restos constructivos que habían sufrido un gran incendio, como el resto de las casas descubiertas, lo que permite pensar que se trata de la Numancia destruida en el 133, como parecen también avalarlo las fechas de C-14 obtenidas, ya que indican un momento de los siglos III-II a.C.

\section{Yacimientos con cerámica de tipo numantino}

En relación con la preocupación por las producciones cerámicas vinculadas con Numancia, hay que destacar el trabajo realizado por M. García Heras (1998: 17-26), que desde un enfoque arqueométrico abordó el estudio para determinar centros de manufactura, áreas de distribución y los procesos tecnológicos en su fabricación, abarcando yacimientos que cubrían una amplia zona.

A la hora de valorar los diferentes yacimientos con sus conjuntos cerámicos, tendremos en cuenta la cronología asignada a los mismos, ya que habrá diferencia si éstos han sido excavados con antelación a los trabajos de Wattenberg (1963), predominando entonces las referencias estratigráficas y la clasificación cerámica de Taracena (1924), o con posterioridad a los realizados por el investigador alemán, que impondrá su ordenación estratigráfica y cronológica. Hemos seleccionado solamente aquellos yacimientos con cerámicas que tienen una gran similitud estilística y conceptual con las numantinas, situándose la mayoría próximos a Numancia, prácticamente en la zona del Alto Duero o en el límite con el Duero medio, aunque haremos referencia a algunos algo más alejados tanto espacialmente como estilísticamente, por el apoyo cronológico que pueden proporcionar a las cerámicas numantinas (fig. 8).

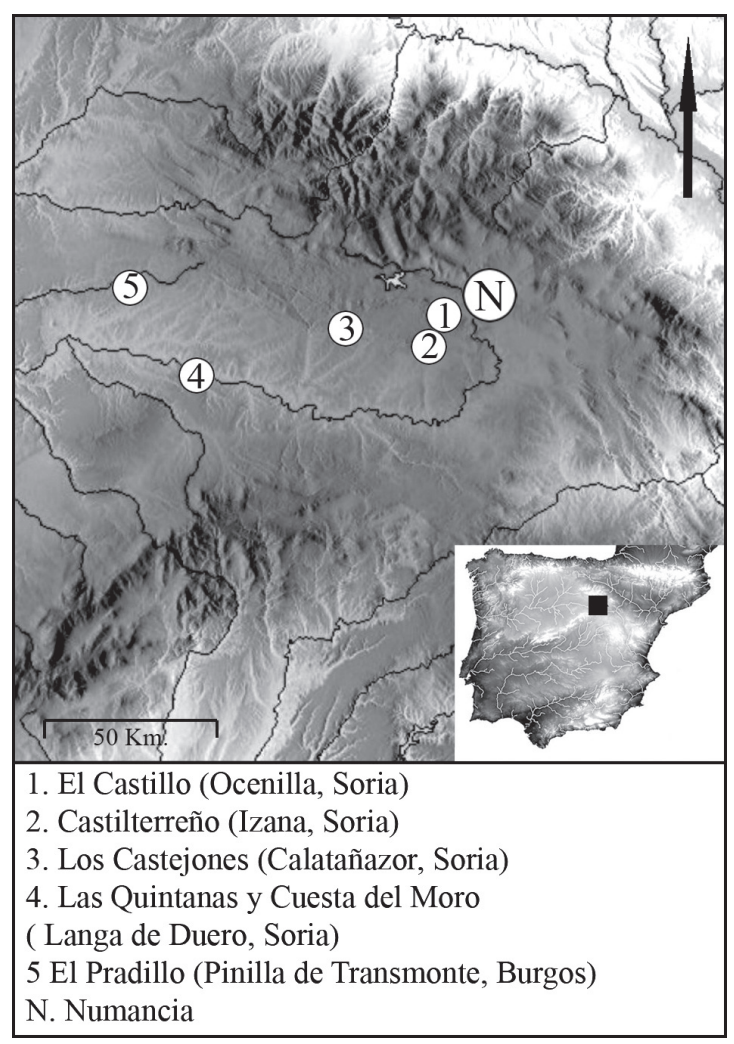

Figura 8.- Mapa de yacimientos citados con cerámica de estilo numantino.

5.1 El Castillo de Ocenilla se encuentra a unos 18 $\mathrm{km}$ de Numancia y fue excavado por Blas Taracena (1932: 37-52; 1941: 122-124). Se trata de una gran fortaleza con potentes defensas que ocupa unas siete hectáreas. Se sitúa en la parte superior de la Sierra de Frentes y Cabrejas, dominando un collado que según su excavador establecería la frontera entre pelendones y arévacos.

En una serie de habitaciones pegadas a la muralla se halló, entre otros restos, un oinochoe o jarra trilobulada que presenta la figura de un guerrero, aislada y pintada en color lleno como en los vasos numantinos de comienzo del primer estilo. Está armado con lanza (soliferrum) y casco de tipo corintio con gran crestón metálico, apoyado en robusto vástago; su vestimenta muestra el uso de la túnica corta, ceñida a la cintura, y el calzón corto hasta por debajo de la rodilla (Taracena 1932: 4). Tara- 
cena situó cronológicamente este yacimiento como de "cultura numantina", desde la segunda mitad del siglo III a.C. y que sería abandonado poco antes de la destrucción de Numancia, en algún episodio producido en los veinte años de enfrentamientos, entre 153 y 133 a.C. (Fig. 9).

5.2 Castilterreño de Izana, a unos $26 \mathrm{~km}$ de Numancia, fue excavado también por Taracena (1927: 3-21). Se trata de un pequeño cerro, rematado en una meseta, que ocupa algo más de 2 ha, defendidas por una muralla. Se trata de un poblado del que se excavaron $2.400 \mathrm{~m}^{2}$, construido en una sola época y destruido en un solo día, reflejándose todas las construcciones en un solo estrato, cubiertas de carbones y cenizas.

Se hallaron un conjunto de cerámicas muy afines a las de Numancia, tanto en sus formas como en los esquemas decorativos, realizados con trazos negros finos y dejando, como fondo de la figura, la superficie roja y pulimentada del vaso; excepcionalmente, algunas piezas llevan engobe blanco. Se han representado casi todos los temas numantinos del grupo de pinturas negras, figuras varoniles, un pez de perfil, estilizado y relleno de semicírculos concéntricos, pero también esquematizaciones de peces, dispuestos en aspas, que tienen como centro un disco solar. Destacan en su decoración una serie de jarros decorados con franjas verticales (con esvásticas, aspas, cruces de brazos iguales, vermiformes, ajedrezados y otros), que sirven como eje para cuatro motivos simétricos, predominando los prótomos de caballos, más o menos estilizados, como es frecuente en Numancia, de los que uno remata su boca en forma de tridente (Taracena 1927: láms. V-X) (Fig. 9). Taracena, atendiendo no sólo a las cerámicas sino también a las fíbulas anulares de navecilla y puñales biglobulares, pero sobre todo a las monedas de tipo celtibérico procedentes de cecas como Bilbilis o Titium y a un bronce de Toletum de tipo indígena pero con leyenda latina, fechó este poblado a finales del s. II e inicios del s. I a.C. poniendo como referencia final las Guerras Sertorianas (Taracena 1927: 3-21).

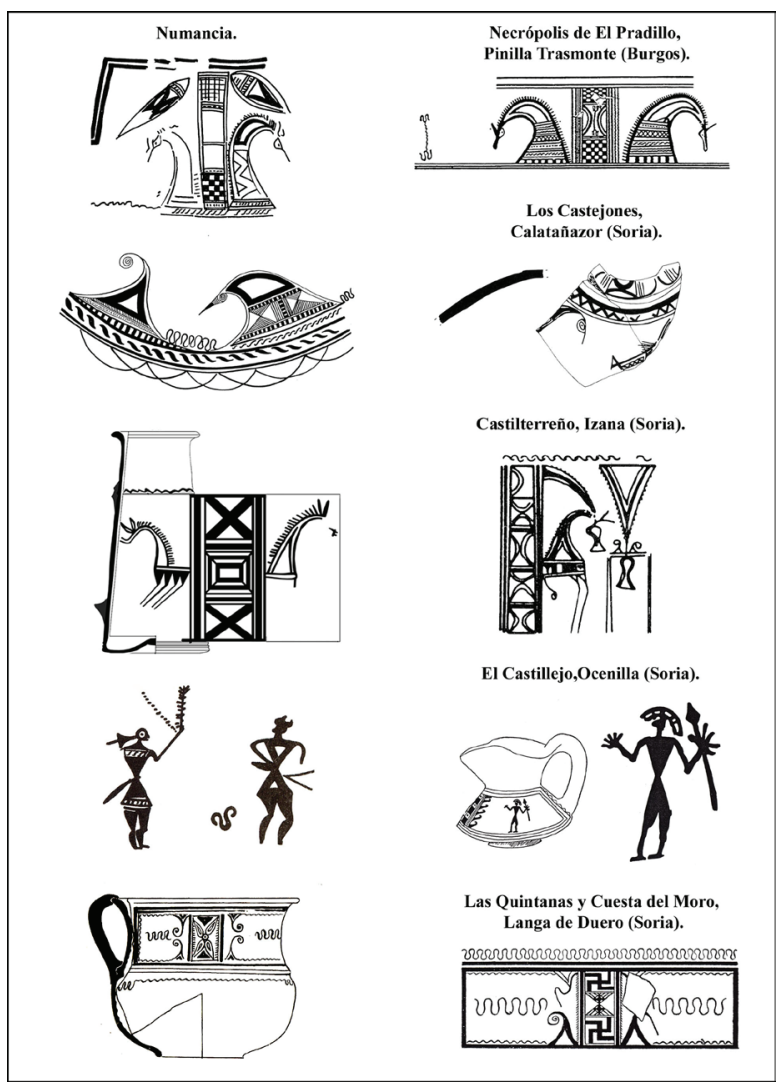

Figura 9.- En la columna de la derecha, esquemas decorativos de las cerámicas de los diferentes yacimientos, relacionados con otros similares de Numancia (columna izquierda). 
5.3 Los Castejones de Calatañazor, donde se quiso situar la ciudad celtibérica de Voluce (Saavedra 1861; Pascual 1991: 36-37; Jimeno 2011: 246), es otro de los yacimientos excavados por Taracena (1926: 15-23), situado a unos $37 \mathrm{~km}$ de Numancia. Este autor indica que entre los restos de cerámica domina en técnica y arte la de tipo numantino: ollas, copa de pie corto y alto fuste, embudos, jarras trilobuladas y otras con pequeñas modificaciones que demuestran pertenecer a diferente alfar. En alguna ocasión se ha engobado en blanco la cerámica para pintar encima, pero por lo general se trata de línea de color negro, representando espirales, esvásticas, vermiformes y combinaciones de semicírculos concéntricos. También destacan sobre todo algunas cerámicas con aves, que presentan una gran concomitancia con las numantinas en la estilización y la decoración de su cuerpo (ajedrezados, líneas quebradas y ocupando el centro dobles espirales), así como el tipo de cabeza y pico, el movimiento de las alas y el remate de la cola en forma triangular, saliendo de los ángulos elementos espiraliformes (Taracena 1926: láms. V-VI). Se fecha este yacimiento desde el s. III y finales del s. II a.C. (Taracena 1926: 21) (Fig. 9).

\subsection{Las Quintanas y Cuesta del Moro de Lan-} ga de Duero, donde Taracena (1929: 31-52; 1932: 52-61; 1941: 89-90) con argumentos contundentes situó la ciudad de Segontia Lanka, está a unos 97 $\mathrm{km}$ de Numancia. La cerámica estampada de esta ciudad parece tener, según este autor (1929: 40; láms. VIII y IX), una mayor relación con las producciones del valle medio del Duero y del occidente meseteño que con la zona del Alto Duero. Por otro lado, los dibujos de las cerámicas le recuerdan a su excavador la plena decadencia del arte numantino (1929: 40-41). En esta interpretación también debió de pesar la cronología que Taracena aplicó a este yacimiento, en un momento avanzado del s. I a.C. y el comedio del s. I d.C. Una revisión reciente ha permitido fecharlo a finales del s. II a.C., e inicios del s. I a.C. hasta las Guerras Sertorianas (Tabernero et al. 2005: 204). Se recogieron también cinco fragmentos con pigmentos negro, blanco y rojo atribuidos a una taza similar a otras que se conocen en Numancia (Taracena 1924: lám. III, 1; Wattenberg 1963: lam. XXXVII, 1027; García Heras 1998: 18) (Fig. 9).

5.5 La Necrópolis de El Pradillo (Pinilla Transmonte, Burgos) se localiza en una terraza del río Esgueva y a un kilómetro del asentamiento del Alto de San Pedro, con una extensión de 17 hectáreas (relacionado con la ciudad celtibérica de Sekobirikes), en la línea de frontera entre arévacos y vacceos. Se conocen enterramientos correspondientes a la Primera Edad del Hierro y a época celtibérica (Moreda y Nuño 1990; Ruiz 2010). Dos tumbas de esta segunda necrópolis proporcionaron un conjunto extraordinario de jarras de tipo numantino (Ruiz 2010: 23), pintadas con motivos geométricos barroquizantes, con un ojo de ave a cada lado del pico vertedor y a veces con motivos figurados: bandas decorativas con prótomos de caballo (con el típico despiece triangular del cuello, seguido de franjas horizontales de líneas onduladas, aspas y ajedrezado) y separados por elementos verticales a modo de metopa (decoradas con aspas, rombos, ajedrezados o elementos simétricos), acompañados de los típicos vermiformes, intercalados entre las representaciones o dispuestos en línea continua, por encima de los cierres que limitan la franja decorativa (Moreda y Nuño 1990: 175) (Fig. 9).

La cronología final para la necrópolis y la ciudad, que acuñaría numario de plata y bronce, habría que situarla a inicios del s. I a.C., muy probablemente con las Guerras Sertorianas. No obstante, sus excavadores hicieron notar la discordancia cronológica entre la propuesta por Wattenberg para las cerámicas (Moreda y Nuño 1990: 179) y la que aportaban las demás evidencias del yacimiento. Por su parte, Sacristán (1986: 132), ya había encuadrado estas cerámicas en el Celtibérico Clásico (en el s. II hasta el I a.C.).

5.6 Otros poblados, más alejados de Numancia y ya en el valle del Ebro, como Los Castellares de Herrera de los Navarros (Zaragoza) muestran en sus esquemas decorativos similitudes con los numantinos; aparte de las esvásticas que están muy generalizadas hay que destacar sobre todo, y a pesar de sus matices diferenciales, una jarra trilobulada de color rojo que está decorada con prótomos de caballo estilizados y otros esquematismos similares que se fechan en la primera mitad del s. II a.C. (Burillo 2005: 115, fig. 2); también en este siglo se han fechado jarros, jarras y vasos con decoración de semicírculos, triángulos contrapuestos dispuestos en franjas horizontales y verticales, en El Palomar de Aragoncillo (Guadalajara), pero que tienen que ver más con el valle del Ebro que con el Alto Duero (Arenas 1999: 110; García Heras 1998: 26)

\subsection{Cerámicas polícromas}

Los hallazgos de cerámicas polícromas que podrían tener relación con Numancia plantean pro- 
blemas para poder concretar una información fiable, ya que los cinco fragmentos con pigmentos negro, blanco y rojo de Langa de Duero ofrecen escasa información (Taracena 1929: 38-40; 1932: 54); en otros casos carecen de contextos bien datados, como los del Amortajado (Barrio et al. 19891990), en el que se encontró un fragmento con pigmento negro y blanco, pero que de acuerdo con la cronología de Wattenberg fue el que se utilizó para situar el yacimiento en el s. I a.C.; finalmente hay que reseñar un fragmento con pigmento rojo y negro hallado en superficie en el Castillejo de Fuensauco (Soria) y que se fecha a mediados del siglo II a.C., de acuerdo con la información que proporciona el yacimiento (Romero 1976: 187; 1991: 400-402). No obstante, la presencia de estos fragmentos permite entrever que algunas cerámicas bícromas y polícromas podrían convivir con otras monócromas esquematizadas.

\section{Discusión}

Uno de los aspectos a destacar es la mayor complejidad estratigráfica que han proporcionado las excavaciones realizadas en las zonas próximas a la muralla, tanto las de Schulten como las de González Simancas. Por el contrario, los trabajos de la Comisión, los realizados por Wattenberg y los del equipo actual, acometidos en las zonas separadas de la muralla dentro de la amplia extensión de la ciudad, han aportado una información coincidente y más reducida: un nivel romano superior y otro inferior celtibérico totalmente alterado, reflejado en una capa de barro rojizo sobre el manto natural y con restos de fragmentos de cerámica celtibéricas y rehundidos de suelos de casas o estancias subterráneas.

Parece evidente que la diferencia entre la información estratigráfica de las zonas próximas a la muralla y el resto de la ciudad no se puede explicar asumiendo que algunas ocupaciones solamente utilizarían las zonas próximas a la muralla. Entendemos que es más razonable pensar que la planificación de la ciudad de época romana respetó la base de la muralla, así como sus construcciones adosadas o vinculadas con ella. Por el contrario, el resto del cerro fue acondicionado para el establecimiento de una nueva urbanística, con más entidad que las anteriores en cuanto a envergadura constructiva y respondiendo a una planificación edilicia uniforme que diseñó e impuso regularmente las calles y las manzanas, así como los espacios de las casas, independientemente de que progresivamente se fueran adaptando y rectificando acorde con las necesidades familiares y de mejora de alineaciones y pavimentos de las calles o espacios públicos.

Es necesario indicar que el esquema urbanístico de esta ciudad no responde a lo que se tiene como modelo clásico romano, ya que se estructura en torno a dos largas calles paralelas, dispuestas de norte a sur, formando una retícula irregular sin dejar espacios libres como plazas o lugares de encuentro. Este tipo de urbanismo encuentra gran semejanza con el conocido en ciudades indígenas, tanto del contexto ibérico como vacceo o meseteño (Ruiz y Molinos 1992: 191ss; Sacristán 2011: 192), con un esquema simple de vía longitudinal central que articula el conjunto y las múltiples calles que la cortan transversalmente, haciendo encuentros escalonados en las intersecciones para desviar el aire. No obstante, se observa en esta ciudad una utilización mayor de la piedra en la base de los cimientos de las casas e incluso en los recrecidos de algunas paredes, frente a la utilización exclusiva, en época celtibérica, de muros de adobe apeados como mucho en una hilada parcial de piedra (Fig. 10).

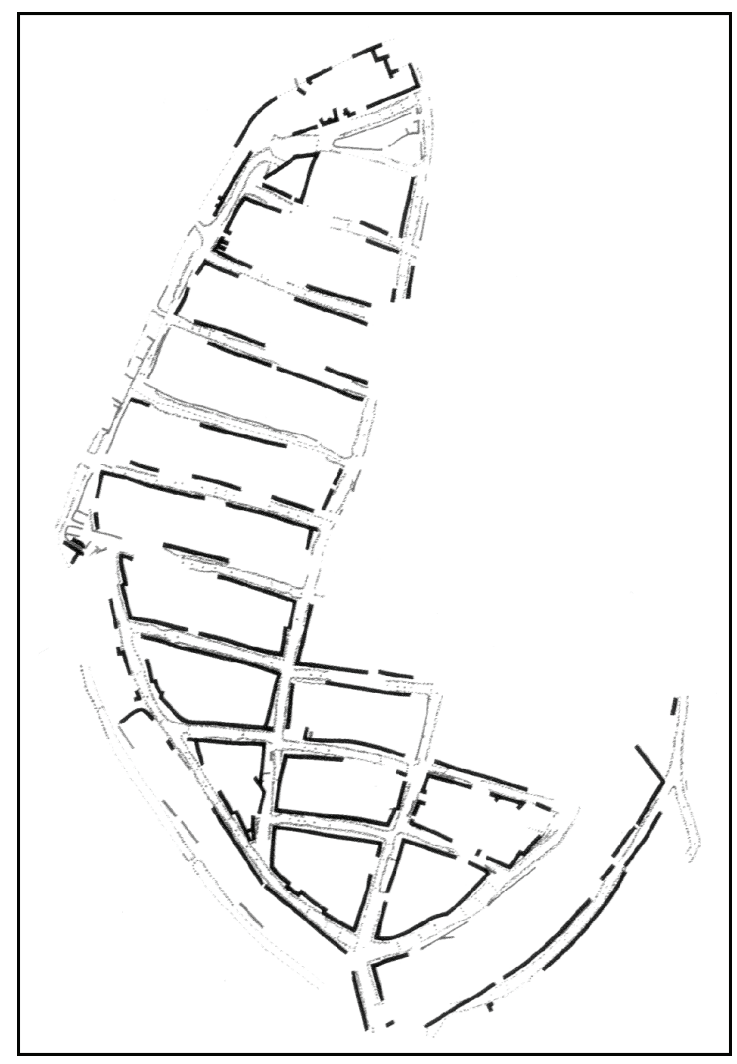

Figura 10.- Plano de Numancia por la Comisión de Excavaciones, con las "dos ciudades superpuestas" visibles actualmente. 
Los datos obtenidos en la excavación de la Manzana XXIII permiten constatar que se trata de una ciudad con una única planificación urbanística inicial, y que para su asiento uniformó el terreno anterior con sucesivos aterrazamientos, tratando de recuperar el manto natural "barriendo", dispersando y apelmazando los restos anteriores, quedando a salvo pequeños resquicios de suelos rehundidos y de estancias subterráneas, por colmatación e igualación, acordes con el acondicionamiento que se pretendía del nivel natural. Sin duda alguna, estos trabajos afectarían, en mayor medida, a los restos de la ciudad o ciudades intermedias; es decir, a las construidas sobre la más antigua, destruida en el 133 a.C., y antes de la romana de época imperial, dejando más huella la primera por haber sido construida directamente sobre el manto natural.

Los restos arqueológicos hallados, fundamentalmente las cerámicas sigillatas itálicas, que están asociadas a la planificación inicial de esta ciudad, indican un momento cronológico para su inicio coincidiendo con la intensa actividad urbanística en época de Augusto. No obstante, si contemplamos el plano de la ciudad, es evidente que mantuvo en general el marco urbanístico inicial pero introduciendo rectificaciones parciales de alineaciones de calles y renovación de suelos, con tendencia a una mayor regularización y mejora de los pavimentos como se puede apreciar en bastantes zonas de la ciudad, lo que pudo suceder más ampliamente a partir de época flavia, cuando recibe el ius Latium, ya que se acusa en este momento una renovación de productos y cerámicas (Romero 1985: 315). Por otro lado, la información de esta manzana, que está situada en una zona céntrica de la ciudad, indica que la Numancia imperial no debió de tener una ocupación intensa muy prolongada, ya que los materiales más recientes (cerámicas y monedas) aportados por la excavación llegan sólo hasta época de Adriano (117-138 d.C.).

Los datos expuestos permiten pensar que desde la destrucción de la ciudad en las Guerras Sertorianas hasta época de Augusto no debió de existir un núcleo urbano en el cerro de La Muela, lo que se ve confirmado por la información que aporta la numismática hallada en la ciudad, que se concentra en torno a tres momentos: con anterioridad al 133 a.C.; desde fines del siglo II hasta el 7572 a.C. y desde época de Augusto al siglo II d. C. (Vidal 1992). La construcción de la ciudad en época de Augusto debió de hacerse con gentes de la zona, lo que explicaría sus características urbanas comentadas, volviendo a recuperar su papel de núcleo de referencia y control de las poblaciones ganaderas del Alto Duero.
Este esquema urbanístico y el concepto de espacio doméstico, un tanto alejados del modelo romano, estarían indicando muy intencionadamente la perduración del substrato prerromano, manteniendo patrones de convivencia espacial diferentes que perdurarán hasta un momento bien entrado de la etapa imperial (Sacristán 2011: 192, 216). Esta urbanística resulta más excepcional si la comparamos con ciudades que son reconstruidas en este momento pero ajustadas a cánones totalmente romanos y con su monumentalidad correspondiente, como Tiermes, Uxama o Clunia. Esta peculiaridad que presenta Numancia debería de servir para plantearnos el ritmo distinto y la profundidad de la implantación romana, acorde con las características diferenciales de los contextos culturales y ambientales, frente a la interpretación estandarizada del modelo monumental clásico.

La consideración de una mayor o menor influencia del mundo indígena o romano en la decoración de la cerámica numantina ha condicionado que tanto Taracena como Wattenberg hayan vinculado esta cerámica con la misma ciudad (la visible de calles de piedras pasaderas), fechándola el primero en el 133 a.C. mientras que el segundo considera que el momento final de esta ciudad debe situarse en el 29 a.C., lo que se explica por el contacto de las cerámicas celtibéricas con la base de esta ciudad.

\section{Conclusiones}

La estratigrafía de Numancia hay que entenderla no sólo por las estructuras evidentes sino también considerando las latentes, es decir, asumiendo que la construcción de la ciudad de época romana conllevó un arrasamiento casi generalizado de los niveles correspondientes a las ciudades inferiores, a excepción de las zonas próximas a la muralla, lo que produjo, de forma generalizada, el contacto de la base de la urbanística romana con los restos removidos de la ciudad más antigua. Esto explica las diferencias interpretativas entre los investigadores, pasando de asumir la existencia de dos ciudades, visibles y coincidentes en gran medida, a las tres, bien documentadas por Schulten, e incluso a las cuatro planteadas por Wattenberg forzando la estratigrafía de Schulten (Wattenberg 1963: 18).

La estratigrafía de Schulten es la más completa y proporciona la información de la urbanística de tres ciudades superpuestas, bien constatadas: la del 133 a.C., la del 75 a.C. y la romana imperial, que guardan relación además con la información que aporta la numismática y que ha proporcionado el conjunto de la ciudad. En este sentido cabe apuntar que la Comisión de Excavaciones no tuvo en cuenta o no 
valoró adecuadamente los trabajos de Schulten, ya que atendiendo exclusivamente a su amplia superficie excavada, unas 6 ha, que pusieron al descubierto algo más de 19 calles y 20 manzanas, solamente pudo constatar las dos fases de la ciudad romana imperial, interpretando la inferior como la celtibérica antigua del 133 a.C., vinculando con ella las estancias subterráneas excavadas en la greda.

Por el contrario, Wattenberg sí prestó atención, como hemos podido ver, a las estratigrafías de Schulten, pero no por completo, ya que éste documenta y reconstruye una de las casas rectangulares del nivel más antiguo, compartimentada en tres estancias, pudiendo acceder desde la primera a través de una trampilla a una estancia subterránea, utilizada para almacenar los alimentos. Sorprende que esto pasara desapercibido para Wattenberg, ya que concibe la ciudad celtibérica como si estuviera construida a base de casas excavadas en la greda natural y no levantada sobre muros, donde por otro lado se documentan algunas de las piezas más relevantes de la cerámica monócroma y polícroma.
La urbanística celtibérica, hallada debajo de la Manzana XXIII, muestra una serie de casas rectangulares, tripartitas y embutidas en el manto natural, similares a las documentadas por Schulten en su nivel inferior, junto a la muralla. Los materiales hallados así como las fechas de C-14 avalan su cronología antigua, s. III-II a.C., lo que unido a la presencia generalizada de una fuerte capa de incendio, permitiría relacionarla con la destrucción de la Numancia histórica, en el 133 a.C.

La revisión de los trabajos anteriores, así como los nuevos datos aportados por las últimas excavaciones, permiten concretar la estratigrafía de Numancia, referente a época celtibérica y romana, pudiéndose diferenciar tres ciudades: la del 133 a.C., documentada en el nivel inferior de Schulten y en la hallada por debajo de la Manzana XXIII; la ciudad que se debió de reedificar tras la destrucción de la anterior y que puede encontrar apoyo en el texto de las fuentes que indica: "Escipión dio Numancia y su territorio a los indigenas que le ayudaron a conquistar la ciudad”, la cual tendría su momento final hacia el 75 a.C.

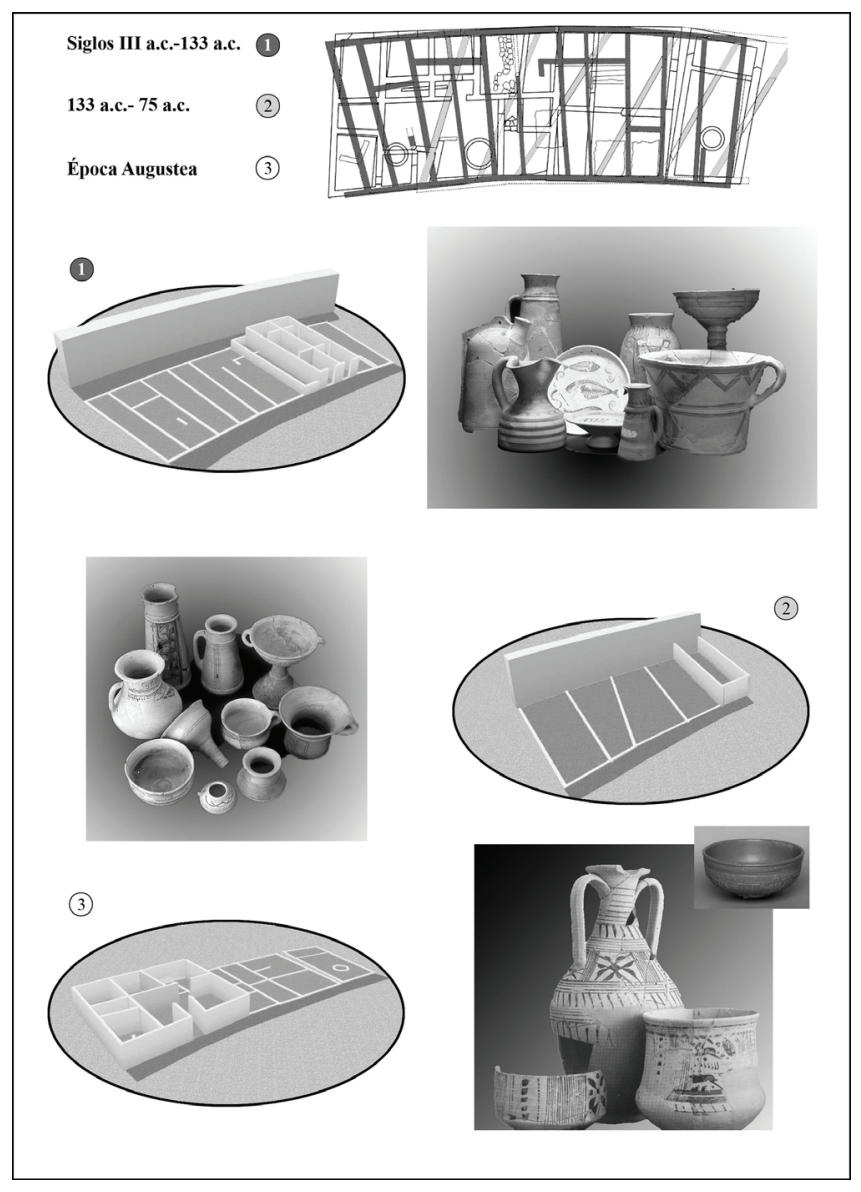

Figura 11.- Las urbanísticas diferenciadas en Numancia con los grupos de cerámicas relacionados. 
como consecuencia de las Guerras Sertorianas; y finalmente la ciudad romana imperial, cuya cronología, según lo aportado por las cerámicas itálicas y la numismática, se situaría en ápoca augustea (Fig. 11).

Finalmente, en relación con la ordenación cronológica de las cerámicas, que ha tenido un claro dirigismo a la hora de fijar la fecha de otros yacimientos celtibéricos o afines, no deja de ser significativa la información que proporcionan los yacimientos comentados que guardan gran afinidad. Las representaciones son estilizadas, desproporcionadas (amplia base para el arranque del cuerpo y cabezas muy pequeñas), con los cuerpos cubiertos de dibujos geométricos, dispuestos en franjas horizontales metopadas. Se trata de uno de los grupos de vasos de barro rojo decorados con pinturas negras, que constituyen el núcleo principal de los hallazgos de Numancia, que Taracena considera de una época avanzada y decadente, coincidiendo su final con la conquista romana en el 133 a.C.; por el contrario, Wattenberg sitúa este grupo de cerámicas a partir del 75 a.C., con anterioridad a las cerámicas polícromas. El conjunto de los yacimientos analizados indican una cronología para este grupo de cerámicas que va desde un momento avanzado del s. II a.C. hasta un momento final en la primera mitad del s. I a.C., ya que la mayoría se vieron afectados por las Guerras Sertorianas.

Menos datos manejamos para ajustar con precisión, si eso es posible, los marcos cronológicos de los distintos grupos de cerámicas numantinas. No obstante, los yacimientos analizados con cerámicas monócromas, con representaciones esquemáticas y estilizadas en negro sobre el fondo rojo de los vasos (algunos engobados en blanco) se pueden fechar, como ha quedado meridianamente claro, entre finales del s. II y la primera mitad del s. I a.C., desarrollándose a partir de este momento la cerámica tardoceltibérica o de tipo Clunia. Si a esto añadimos la ausencia de la ciudad propuesta por Wattenberg entre el 75 y el 29 a.C., en la que llegando en su momento final se desarrollarían las cerámicas polícromas, no queda otra solución que dirigir nuestra mirada a la ciudad antigua, destruida en el 133 a.C., lo que se vería apoyado por hallarse este tipo de cerámica en las "cuevas" o estancias subterráneas y sobre el manto natural, en contacto con la base de la ciudad romana, encontrando así explicación la interpretación que hacemos del "barrido" realizado al construir la urbanística romana, que borró casi por completo las ciudades anteriores.

\section{Notas}

1. Este articulo es fruto de los trabajos realizados en el marco del Plan Director de la Junta de Castilla y León, a través de un convenio con la Universidad Complutense.

\section{REFERENCIAS BIBLIOGRÁFICAS}

Almagro Basch, M. (1951): Estado actual de la clasificación de la cerámica ibérica, Crónica del VI Congreso Arqueológico de Sureste Español, Cartagena: 137-146

Arenas, J. (1999): La Edad del Hierro en el Sistema Ibérico Central, España. B.A.R. International Series S 780, Oxford.

Barrio, R.; Arellano, O.L.; Lerín, M.; Heras, E.; Ruíz, A.; Tarancón, M.J. (1989-1990): El Amortajado, un nuevo yacimiento celtibérico en la provincia de Soria. Nvmantia, 4: 149-158.

Bosch Gimpera, P. (1958): Todavía el problema de la cerámica ibérica. Cuadernos del Instituto de Historia, Serie Antropológica, 2 (Univ. Autónoma de México).

Burillo, F. (2005): Los Castellares de Herrera de los Navarros. Los Celtíberos. Tras la estela de Numancia (A. Jimeno, ed.), Junta de Castilla y León, Diputación de Soria, Ayuntamiento de Soria y Caja Duero, Salamanca: 109-117.

Espinosa, U. (1984): Las ciudades de Arévacos y Pelendones en el Alto Imperio. Su integración jurídica. Symposium de Arqueología Soriana, Soria: 307-324.

Fernández Moreno, J.J. (1997): El poblamiento prehistórico de Numancia. Estudios y Catálogos 7. Junta de Castilla y León, Salamanca.

García Heras, M. (1998): Caracterización de la producción cerámica numantina. B.A.R. International Series S 692, Oxford.

González Simancas, M. (1926): Las fortificaciones de Numancia. Excavaciones practicadas para su estudio. Junta Superior de Excavaciones y Antigüedades, 74, Madrid.

Jimeno, A. (2011): Las ciudades celtibéricas de la Meseta Oriental. Complutum, 22, 2: 223-276.

Jimeno, A.; Chaín, A. (2005-2006): El Plan General de trabajos en Numancia, de 1962, y los problemas estratigráficos. Homenaje al Profesor D. Antonio Beltrán Martínez, Kalathos, 24-25: 239-258. 
Jimeno, A.; Revilla, M.L.; De la Torre, J.I.; Berzosa, R.; Martínez, J.P. (2002): Numancia (Garray, Soria). Guía Arqueológica. Asociación de Amigos del Museo Numantino y Junta de Castilla y León, Soria.

Jimeno, A.; Tabernero, C. (1996): Origen de Numancia y su evolución urbana. Homenaje al Profesor Manuel Fernández Miranda (M.A. Querol y T. Chapa, eds.) Complutum-Extra, 6: 415-432.

Liceras, R.; Santos, A.; Quintero, S.; Chaín, A.; De la Torre, J.I., Jimeno, A. (2012): Nueva iconografía en una vasija de Numancia. VII Simposio sobre Los Celtíberos. Nuevos descubrimientos, nuevas interpretaciones (F. Burillo, ed.), Centro de Estudios Celtibéricos de Segeda (preactas).

MoredA, J.; Nuño, J. (1990): Avance al estudio de la necrópolis de la Edad del Hierro de "El Pradillo", Pinilla de Trasmonte (Burgos). II Simposio sobre Los Celtíberos. Necrópolis Celtibéricas” (F. Burillo, ed.), Institución Fernando el Católico, Zaragoza: 171-182.

Palol, P. (1972): Algunas reflexiones sobre Numancia y Clunia. Numancia, crónica del coloquio conmemorativo del XXI centenario de la epopeya numantina (A. Beltrán, ed.), Monografías Arqueológicas 10, Zaragoza: 101-106.

Pascual Díez, A.C. (1991): Carta Arqueológica de Soria. Zona Centro. Diputación Provincial de Soria, Soria.

Romero Carnicero, F. (1976): Las cerámicas polícromas de Numancia. Centro de Estudios Sorianos, Valladolid.

Romero Carnicero, M.V. (1985): Numancia I. La Terra Sigillata. Excavaciones Arqueológicas en España, Ministerio de Cultura, Madrid

Romero Carnicero, F. (1991): Los Castros de la Edad del Hierro en el Norte de la provincia de Soria. Studia Archaeologica, 80, Valladolid

Ruiz, A.; Molinos, M. (1992): Los Iberos, Crítica, Barcelona.

Ruíz Vélez, I. (2010): Las necrópolis de la primera Edad del Hierro de El Pradillo, (Pinilla de Trasmonte, Burgos). Institución Fernán González, Burgos.

SAAVEdra, E. (1861): Descripción de la vía romana entre Uxama y Augustróbriga. Memoria de la Real Academia de la Historia, IX. Madrid.

SaCristán, J.D. (1986): La Edad del Hierro en el valle medio del Duero. Rauda (Roa, Burgos). Valladolid.

SACRISTÁn, J.D. (2011): El urbanismo vacceo. Complutum, 22, 2: 185-222.

Santos, A.; Liceras, R.; Quintero, S.; Chaín, A.; De la Torre, J.I.; CatanZariti, G.; Dietz, Ch.; Viana, S.; Jimeno, A. (2012): Molde singular de fíbula anular hallado en la ciudad celtibérica de Numancia. VII Simposio sobre Los Celtíberos. Nuevos descubrimientos, nuevas interpretaciones (F. Burillo, ed.), Centro de Estudios Celtibéricos de Segeda (preactas).

Schulten, A. (1945): Historia de Numancia. Editorial Barna, Barcelona.

Tabernero, C.; Heras, E.; Benito, J.P.; Sanz, A. (2005): Segontia Lanka. Celtíberos. Tras la estela de Numancia (Jimeno, A., ed.), Junta de Castilla y León, Diputación de Soria, Ayuntamiento de Soria y Caja Duero, Salamanca: 197-204.

TARACEnA, B. (1924): La cerámica ibérica de Numancia. Madrid.

TARACEnA, B. (1926): Excavaciones en diversos lugares de la provincia de Soria. Junta Superior de Excavaciones y Antigüedades, 75, Madrid.

Taracena, B. (1927): Excavaciones en la provincia de Soria y Logroño. Junta Superior de Excavaciones y Antigüedades, 86, Madrid.

TARAcena, B. (1929): Excavaciones en la provincia de Soria y Logroño. Junta Superior de Excavaciones y Antigüedades, 103, Madrid.

Taracena, B. (1932): Excavaciones en la provincia de Soria. Junta Superior de Excavaciones y Antigüedades, 119, Madrid.

Taracena, B. (1941): Carta Arqueológica de España. Soria. Instituto Diego Velázquez, C.S.I.C., Madrid.

VidAL, J. M. (1992): Hallazgos numismáticos de la Meseta Oriental (Ciclo Colonial). Universidad Complutense (Tesis Inédita).

Wattenberg, F. (1959): Los problemas de la cultura celtibérica. Primer Symposium de Prehsitoria de la Península Ibérica, Pamplona: 151-164.

Wattenberg, F. (1963): Las cerámicas indígenas de Numancia. Bibliotheca Praehistorica Hispana, IV, Madrid.

Wattenberg, F. (1972): Informe sobre los trabajos realizados en las excavaciones de Numancia. Numancia. Crónica del Coloquio Conmemorativo del XXI Centenario de la Epopeya Numantina (A. Beltrán, ed.), Monografías Arqueológicas 10, Zaragoza: 59-73. 